\title{
Cuando la sociedad civil habla, ¿los jueces escuchan?: análisis de las audiencias públicas ante el Tribunal Constitucional chileno y su impacto en las sentencias constitucionales
}

\author{
When Civil Society Speaks, Do the Judges Listen?: Analysis \\ of the Public Hearings before the Chilean Constitutional Court \\ and their Impact on the Constitutional Judgments
}

Quando a sociedade civil fala, os juízes escutam?: análise das audiências públicas do Tribunal Constitucional chileno e seu impacto nas sentenças constitucionais

\author{
TANIA BUSCH VENTHUR \\ ABRAHAM QUEZADA SALDÍAS ${ }^{* *}$
}

FECHA DE RECEPCIÓN: 22 DE DICIEMBRE DE 2020. FeCHA DE APROBACIÓN: 7 DE JULIO DE 2021

Doi: https://doi.org/10.12804/revistas.urosario.edu.co/sociojuridicos/a.10093

Para citar este artículo: Busch Venthur, T., \& Quezada Saldías, A. (2022). Cuando la sociedad civil habla, ¿los jueces escuchan?: análisis de las audiencias públicas ante el Tribunal Constitucional chileno y su impacto en las sentencias constitucionales. Estudios Socio-Jurídicos, 24(1), 201-232. https://doi.org/10.12804/revistas.urosario. edu.co/sociojuridicos/a.10093

\section{RESUMEN}

El presente trabajo analiza una década de audiencias públicas convocadas por el Tribunal Constitucional chileno, buscando determinar si su realización ha impactado en la argumentación de sus sentencias constitucionales. La pregunta es si su realización enriquece la deliberación y democratiza la interpretación constitucional, como se señala

* Abogada, licenciada en Ciencias Jurídicas y Sociales por la Universidad de Concepción; magíster en Ciencias Jurídicas y doctora en Derecho por la Pontificia Universidad Católica de Chile. Profesora asistente, Área de Derecho Público, Facultad de Derecho, Universidad Andrés Bello(Chile).Correos electrónicos: tania.busch@unab.cl, taniabusch@gmail.com ORCID: https://orcid.org/0000-0002-6943-2595

** Abogado, licenciado en Ciencias Jurídicas por la Universidad Andrés Bello. Profesor ayudante, Área de Derecho Público, Facultad de Derecho, Universidad Andrés Bello (Chile). Correos electrónicos: a.quezadasaldias@uandresbello.edu, quezadasaldias@gmail.com. ORCID: https://orcid.org/0000-0003-4753-0044 
desde la teoría. Se expone el tratamiento teórico de la institución, con especial énfasis en las experiencias comparadas latinoamericanas. Luego, se lleva a cabo un análisis empírico de las sentencias que han resuelto casos en que convocaron audiencias, con el objeto de identificar qué criterios utiliza el tribunal para llamar a dichas audiencias, si es que se hace referencia a estas en la argumentación de los fallos, y, de ser así, con qué rol argumentativo se las alude. El trabajo concluye que la información y argumentos que la sociedad civil aporta en las audiencias públicas son subutilizados en el proceso de argumentación de las sentencias judiciales, y que el potencial deliberativo y democratizador de la institución respecto de los procesos de control de constitucionalidad no se despliega en la práctica.

Palabras clave: audiencias públicas; Tribunal Constitucional chileno; sentencias constitucionales; participación de la sociedad civil; juez constitucional.

\section{ABSTRACT}

This paper presents the analysis of a decade of public hearings convened by the Chilean Constitutional Court, seeking to determine if their conduct impacted the argumentation of its constitutional judgments. The question is whether those hearings enrich the deliberation and democratize the constitutional interpretation, as indicated by the theory. The authors expose the theoretical treatment of the institution with special emphasis on comparative Latin American experiences. Then, they analyze the judgments that resolve cases in which hearings have been convened in order to identify what criteria the court used, were they referenced in the argumentation of the rulings? If they were referenced, what was their argumentative role? The work allowed concluding that the information and arguments contributed by civil society to public hearings are underused in the argumentation processes of judicial decisions and that the deliberative and democratizing potential of the institution regarding constitutionality control processes does not deploy in practice.

Keywords: Public hearings; Chilean Constitutional Court; constitutional judgments; participation of civil society; constitutional judge.

\section{RESUMO}

Este artigo analisa uma década de audiências públicas convocadas pelo Tribunal Constitucional do Chile, buscando determinar se sua realização teve impacto na argumentação de suas sentenças constitucionais. O questionamento é se sua realização enriquece a deliberação e democratiza a interpretação constitucional, como indica a teoria. O tratamento teórico da instituição é exposto, com especial ênfase nas experiências comparativas latino-americanas. Em seguida, é realizada uma análise empírica das sentenças que resolveram casos em que foram convocadas audiências, a fim de identificar quais os critérios que o tribunal utiliza para convocar as referidas audiências, se são referidas na argumentação das decisões, e em caso afirmativo, com qual papel argumentativo elas são referidas. $O$ trabalho conclui que as informações e argumentos oferecidos pela sociedade civil nas audiências públicas são subutilizados no processo de argumentação das decisões judiciais, e que o potencial deliberativo e a democratização da instituição no que diz respeito aos processos de controle de constitucionalidade, não são implantados na prática.

Palavras-chave: audiências públicas; Tribunal Constitucional do Chile; sentenças constitucionais; participação da sociedade civil; juiz constitucional. 


\section{Introducción}

El término 'audiencias públicas' es multívoco, y puede hacer referencia a diversas formas institucionales de transparencia, apertura y participación ciudadana. ${ }^{1}$ En este trabajo se entenderá por audiencias públicas (AP) aquellas que se realizan dentro de un proceso en que se resolverá una controversia sobre el significado de la Constitución, a través del ejercicio de la jurisdicción constitucional, dentro del cual se convoca a personas o instituciones que no son parte, ni órgano constitucional legitimado o interesado de acuerdo con el ordenamiento jurídico, a exponer oralmente ante el órgano que ejerce jurisdicción constitucional sobre la controversia que se está conociendo, para ilustrar a este respecto de las circunstancias y consecuencias fácticas o jurídicas de la controversia constitucional sometida a su conocimiento.

Esta herramienta permite convocar la intervención de la sociedad civil para que se manifiesten a los jueces constitucionales sus argumentos y apreciaciones sobre el conflicto constitucional del que se conoce, informando así a la jurisdicción constitucional sobre las consecuencias de la sentencia.

Las AP se han incorporado recientemente como institución en las jurisdicciones constitucionales de Latinoamérica, aproximadamente desde la segunda mitad de la década de 2000. Su implementación ha estado generalmente asociada a reformas constitucionales o procesos de transformación de las cortes constitucionales en que se busca reforzar la nueva institucionalidad naciente o legitimar las cortes luego de procesos de reestructuración de estas (Abramovich, 2013; Gargarella, 2013; Pou, 2017; Sancari, 2015; Tushnet, 2015).

La convocatoria a estas audiencias es excepcional y facultativa para los tribunales. Por regla general se convocan en casos que concita alto interés de la ciudadanía o cuya resolución tendrá un evidente efecto o impacto político. Esta novedad procedimental promete estrechar los vínculos entre las instituciones y la ciudadanía, trasladando modos de

Existen AP dentro de los procedimientos judiciales, como formas de participación ciudadana dentro de los procedimientos administrativos o como una forma de control y transparencia dentro de los procesos de nominaciones a altas magistraturas, entre otras. 
participación que usualmente se asocian a los espacios políticos tradicionales hacia espacios reservados al poder judicial, buscando que las decisiones de estos sean sensibles a la voluntad de la ciudadanía y la incluyan, en algún modo, en los procesos decisorios.

Las expectativas que ha generado esta novedad procedimental son altas. Como destacan Sáenz y Barrera, las AP ponen en primer plano las tensiones y relación conflictiva entre la necesidad de que el significado jurídico constitucional provenga de la ciudadanía y que esta sienta como propia a la Constitución (ideal del autogobierno); y, por otro lado, la necesidad estatal de establecer un derecho único en que corresponde a las cortes la voz experta autorizada técnica y estatalmente para establecer dicho significado (2020, p. 284).

Aunque no está todavía claro qué racionalidad o tipo de argumentación debe tener cabida en las AP, parece ser que, a diferencia de los amicus curiae (cuya finalidad es que un experto ilustre al tribunal sobre un punto de derecho), estas se distinguen por dar lugar dentro del proceso de control de constitucionalidad a consideraciones o argumentos extrajurídicos, ${ }^{2}$ invitándose a comparecer a la sociedad civil y a quienes se verán involucrados por el impacto que la sentencia tendrá más allá de las partes. ${ }^{3}$

El objetivo de esta investigación es determinar si, en el caso chileno, las AP han logrado cumplir con la expectativa de enlazar la participación de la sociedad civil y la expresión de sus argumentos, antecedentes y discursos con la racionalidad jurídica y su resultado: la sentencia constitucional que resuelve el caso.

En cuanto a la metodología utilizada, se analizaron empíricamente las sentencias que resuelven casos en que se ha convocado a AP insertas en procesos de control de constitucionalidad convocadas por el Tribunal Constitucional chileno (TCCh) durante una década. El trabajo

2 Santos señala que uno de los aspectos reiteradamente observados en las audiencias públicas convocadas por el Supremo Tribunal Federal de Brasil es la ausencia de debates o exposiciones con argumentos predominantemente jurídicos por parte de los participantes. Esto apuntaría a asociar a las audiencias con la obtención de informaciones de orden técnico (2017, p. 246).

3 En Chile los conceptos de AP y amicus curiae no están claramente diferenciados, como sí parecen estarlo en las experiencias brasileras y argentinas (Santos, 2017; Benedetti \& Sáenz, 2016). 
revisa todas las audiencias realizadas entre los años 2007 a 2018, ${ }^{4}$ identificando el perfil de las causas en que las audiencias han sido convocadas, y analizando si en la argumentación de las sentencias que las resuelven se han incorporado las argumentaciones y antecedentes expresados por los participantes. El universo de sentencias por analizar fue identificado por dos vías: por una parte, se encontraron a través del buscador inserto en la página web del TCCh, ${ }^{5}$ en el cual se pone como criterio de búsqueda 'audiencia pública', que arroja como resultados las noticias que informan de haberse dictado una resolución que convoca a AP en una causa determinada, indicando la fecha y rol de la causa. Con esto es posible acceder al expediente de esta, donde está consignado todo aquel que solicita ser oído en cada audiencia. Por otra parte, las AP están disponibles en el canal de YouTube del TCCh, ${ }^{6}$ lo que permite revisar las intervenciones de todos los participantes. ${ }^{7}$

En los párrafos que siguen i) se expondrá cuál es el objetivo normativo de la institución de las AP conforme con la literatura; ii) se revisarán los resultados de estudios efectuados en Latinoamérica sobre la experiencia de AP y su impacto en las sentencias constitucionales; iii) se estudiará la totalidad de AP convocadas por el TCCh en el período 2007 a 2018, identificando en el ejercicio de qué competencia del TCCh las ha convocado y cuál ha sido el criterio de selección de causas en las que se han convocado, así como las menciones expresas a los argumentos y antecedentes señalados en las audiencias; para, finalmente, iv) determinar si la realización de estas audiencias ha significado, en

4 La determinación del universo por analizar excluye audiencias posteriores. Al momento de hacer el análisis, se trabajó con el universo total existente. Con posterioridad se realizaron audiencias públicas, pero estas no se incorporaron, puesto que una década establece un marco temporal adecuado para evaluar una institución. Más relevante que eso es que las audiencias realizadas con posterioridad se verificaron de forma telemática, por lo tanto, en condiciones distintas para la participación de la sociedad civil y su recepción por parte de los ministros. De ahí que, a nuestro parecer, su incorporación agregaría elementos que pudieran distorsionar la evaluación, perjudicando, más que favoreciendo, las conclusiones de la investigación.

5 https://www.tribunalconstitucional.cl/

6 https://www.youtube.com/user/TCCHILE2

7 En cuanto a quienes han participado en las audiencias, grosso modo, se pueden agrupar en centros de estudios, asociaciones gremiales y organizaciones no gubernamentales, y universidades, entre otros. El análisis pormenorizado del perfil de quienes exponen en el TCCh en las AP es materia de una investigación en desarrollo que excede el objeto y extensión del presente trabajo. 
los hechos, un enriquecimiento de la deliberación dentro del proceso de control de constitucionalidad, impactando en la argumentación de los fallos que dicta el TCCh.

\section{Objetivo institucional de las audiencias públicas}

En la literatura existe consenso respecto a que la convocatoria a AP encuentra su inspiración en el ideal deliberativo. Se entiende que constituyen una forma institucionalizada de participación de la ciudadanía ante la jurisdicción constitucional. A través de estas se canalizan las diversas concepciones e interpretaciones que existen en la sociedad sobre una controversia constitucional, presentándose argumentos respecto a los aspectos controvertidos involucrados en el caso, sean interpretaciones sobre el significado de la carta fundamental y los argumentos jurídicos que la sustentan, sean consecuencias fácticas de un caso para conocimiento de los jueces constitucionales.

Sin embargo, no existe un tratamiento teórico ni sistemático de las audiencias que permita perfilar la institución e identificar con claridad cuál es el objetivo institucional que buscan concretar. Es decir, la pregunta ¿para qué se abre el proceso de deliberación judicial a la sociedad civil? no encuentra una única respuesta, sin que se pueda saber qué tipo de insumos, dentro del proceso y para el caso que están conociendo, esperan obtener los jueces constitucionales cuando disponen convocar a audiencias. ${ }^{8}$

La revisión de la literatura existente sobre AP (Abramovich, 2013; Benedetti \& Sáenz, 2016; Benedetti \& Sáenz, 2018; Correa \& Mendes, 2016; Correia, Da Silva \& Tenorio, 2018; Giuffré, 2016a, 2016b; Hennig, 2014; Leal, Herdy \& Massadas, 2018; Lorenzetti, 2013; Sacristán, 2009; Sáenz \& Barrera, 2020; Sancari, 2015; Santos, 2017; Sola, 2013),

8 Esto es importante de clarificar, ya que otra forma de abordar el para qué se refiere a la motivación de las cortes para implementar estas instancias, u otras prácticas dialógicas en que se involucran los tribunales constitucionales. Mirado en forma macro, se puede ver como una actuación estratégica que busca recuperar una legitimidad institucional perdida, o reforzar una debilitada (Gargarella, 2019). 
así como de su regulación en otros países latinoamericanos, ${ }^{9}$ permite concluir que coexisten dos objetivos institucionales: uno de orden técnico o fáctico y otro de orden normativo, sin que esté claro cuál es el principal o dominante. El primero, técnico o fáctico, dice relación con que las AP amplían la participación para enriquecer la deliberación, aportando antecedentes fácticos o técnicos que están fuera del ámbito de conocimiento de los jueces constitucionales. El segundo objetivo, normativo, se vincula con el potencial democratizador y legitimador de las AP en el ejercicio de la jurisdicción constitucional al incorporar al proceso a otros intérpretes constitucionales, en la lógica de la sociedad abierta de los intérpretes de la Constitución (Häberle, 2008). La idea central es que, en la medida que se aumenta la deliberación dentro del proceso de control de constitucionalidad, se morigeraría la objeción democrática a la justicia constitucional.

Como han señalado Correa y Mendes, la percepción que existe sobre el potencial de las AP en la jurisdicción constitucional parece basarse en los siguientes pilares conceptuales: legitimidad, participación e información. La legitimidad democrática del proceso decisorio se profundiza por la participación que las audiencias promueven, en la medida que generan decisiones mejor informadas, considerando no solo la complejidad técnica de los temas en cuestión, sino también el pluralismo moral y las diversas posiciones políticas que existen dentro de la sociedad (Correa \& Mendes, 2017, p. 144). La idea subyacente a la

9 Por ejemplo, en Argentina la Acordada 30/2007 señala que "[...] La participación ciudadana en actos de esa naturaleza y la difusión pública del modo en que esta Corte conoce de los asuntos en que, con carácter primordial, ha de ejercer la jurisdicción más eminente que le confiere la Constitución Nacional, permitirá poner a prueba directamente ante los ojos del país, la eficacia y objetividad de la administración de justicia que realiza este Tribunal". En Brasil los artículos 13, XVII, y 21, XVII, del Reglamento Interno del Supremo Tribunal Federal de Brasil indican que la finalidad de convocar a estas audiencias es "escuchar el testimonio de las personas con experiencia y autoridad en una determinada materia, siempre que considere necesario aclarar las cuestiones o circunstancias de hecho, con repercusión general y de interés público pertinente, debatidas en el marco del Tribunal". Los artículos 12 y 13 del Decreto 2067 de 1991, "por el cual se dicta el régimen procedimental de los juicios y actuaciones que deban surtirse ante la Corte Constitucional", determinan que se cita a "organizaciones privadas y a expertos en las materias relacionadas con el proceso" para que den "sus conceptos sobre puntos relevantes para la elaboración del proyecto de fallo". En México la parte final del considerando séptimo del Acuerdo General 2/2008 establece que el pleno de la Suprema Corte de Justicia de la Nación podrá convocar audiencias cuando se trate de "asuntos de gran entidad y trascendencia para la sociedad mexicana", para que "los interesados puedan exponer sus puntos de vista sobre los temas a que se refieren dichos asuntos". 
implementación de las AP es que, entre más puntos de vista y diversidad de actores se oigan, mejores serán las condiciones de protección de los intereses de los involucrados en la decisión constitucional, menor será la tensión democrática de la justicia constitucional con la democracia y las deliberaciones constitucionales serán cualitativamente más complejas (Santos, 2017, p. 240). La literatura se ha mostrado ampliamente confiada en el potencial democratizador de las experiencias de apertura de la jurisdicción constitucional y su efecto en relación con la objeción contramayoritaria.

\section{Las audiencias públicas en los estudios empíricos}

El optimismo teórico respecto del potencial democratizador y deliberativo de las AP contrasta con las conclusiones, menos entusiastas, de los estudios empíricos realizados. Aunque pocos y con matices, los resultados van en una línea menos auspiciosa. En general, no se observa que la práctica de convocar a AP haya redundado en un robustecimiento significativo en la deliberación, siendo sus resultados subóptimos en relación con el potencial de la institución (Benedetti \& Sáenz, 2016; Nosetto, 2018; Santos, 2017; Correa \& Mendes, 2017).

Aunque AP existen en distintos países de Latinoamérica, ${ }_{10}^{10}$ la literatura en la materia es relativamente escasa. Su desarrollo ha sido más significativo en Argentina y, principalmente, Brasil. Esto resulta relevante para este trabajo, desde que solo en estos sistemas se hallaron estudios que hayan evaluado el impacto de las AP en la deliberación y sentencias de la jurisdicción constitucional. El método empleado por los estudios ha sido textualista, analizando las referencias expresas de las sentencias a las AP para, desde ahí, construir categorías y sacar conclusiones.

En Argentina, el estudio más destacado es el de Benedetti y Sáenz. Los autores analizaron la totalidad de las AP realizadas y sus menciones en las sentencias en el período investigado. ${ }^{11}$ La conclusión a la que

10 Argentina, Brasil, Chile, Colombia, México y Ecuador.

11 Se analizó la totalidad de AP efectuadas durante el período comprendido entre los años 2004 y 2017. 
arriban es que la Corte hizo una subutilización del material argumentativo generado en las audiencias. Las referencias de los fallos a las AP públicas en ocasiones no existen, en ocasiones son meramente formales y otras veces las referencias tienen usos argumentativos de diversa índole e intensidades (Benedetti \& Sáenz, 2018, p. 121). Afirman que la selección de argumentos es discrecional, pudiendo prescindir a veces totalmente del debate de las audiencias $\mathrm{y}$, a veces, seleccionar tramos de los argumentos, dejando otros fuera.

En Brasil se encuentran mayores estudios de corte empírico. De especial relevancia resulta el estudio de Santos, que, de la totalidad de las audiencias realizadas por el Supremo Tribunal Federal de Brasil en el período investigado, ${ }^{12}$ escogió dos de ellas y llevó a cabo un estudio de caso. También en este trabajo se optó por verificar solo las menciones expresas a las audiencias que los ministros consignaron en el texto de los fallos. Su conclusión es similar a la del estudio del caso argentino. Santos señala que las AP se revelaron como un instrumento cuya función deliberativa está por debajo del potencial de calidad y legitimidad democrática esperada. Los resultados obtenidos demuestran que algunas audiencias se han prestado a una finalidad meramente retórica dentro del proceso de construcción argumentativa. Por la magnitud y posibilidades al alcance de la figura transformadora del proceso decisorio, las AP pueden ser mejor aprovechadas (Santos, 2017, p. 267). Por su parte, Leal, Herdy y Massadas, respecto de las AP del Supremo Tribunal Federal de Brasil, han concluido que esta herramienta se ha utilizado de modo inconsistente e incoherente, ya que, por un lado, no hay claridad en cuanto a los criterios de elegibilidad de las causas en que se convoca y de la naturaleza de la cuestión en que debe convocarse a AP; y, por otro, se asigna una función de legitimación democrática a AP que se presenta como la convocatoria a expertos para aclarar cuestiones de hecho (Leal et al., 2018, p. 333).

A la luz de estas conclusiones, cabe repensar si la realización de AP públicas significa realmente una mejora de la deliberación dentro del proceso de control de constitucionalidad. Este trabajo se propone

12 En este caso, Santos considera las 18 AP convocadas hasta el año 2013 por el Supremo Tribunal Federal de Brasil (2017, p. 240). 
evaluar cuál ha sido el impacto de la realización de las AP convocadas por el TCCh en relación con la argumentación de sus sentencias.

Se utilizará el criterio textualista base de las investigaciones de los trabajos de Santos y Benedetti y Sáenz. Esto es, evaluar y analizar considerando solo las menciones expresas de las sentencias a los argumentos vertidos en las AP. No se avanza en otro tipo de impactos que pudieron haber causado las AP en los jueces (impacto emocional, por ejemplo, o de disposición favorable o adversa a alguna de las partes, etc.) por las dificultades metodológicas que implicaría este tipo de estudios, aunque no se descarta que estos otros impactos pudieran ser relevantes para el resultado del proceso constitucional.

De este modo, se pretende determinar si para el caso del TCCh la realización de AP ha redundado en la obtención de información o argumentos jurídicos que hayan enriquecido la deliberación y los fundamentos que los ministros del TCCh exponen en sus sentencias, cumpliéndose (o no) las expectativas de la teoría en relación con las AP.

\section{Regulación de las audiencias públicas en el ordenamiento jurídico chileno}

A diferencia de lo que sucede en otras jurisdicciones constitucionales latinoamericanas, las AP que convoca el TCCh son el resultado de una práctica del tribunal y no una institución jurídica que esté regulada como tal de forma organizada y coherente. La Ley Orgánica Constitucional del Tribunal Constitucional 17997 (LOCTC) no las menciona ni las regula, y tampoco existe a su respecto un auto acordado que las reglamente clara y sistemáticamente. Solo es posible encontrar referencias a las audiencias como una cuestión tangencial en el Auto Acordado "Normas sobre lobby, registros públicos con fines de transparencia, imparcialidad, independencia y publicidad" del 30 de diciembre de 2014 .

Cuando el TCCh convoca a AP, dicha convocatoria se funda en el artículo 37 de la LOCTC. Esta disposición, inserta dentro del "Título I. Normas generales de procedimiento", faculta al tribunal para "decretar las medidas que estime del caso tendientes a la más adecuada sustanciación y resolución del asunto de que conozca". 
Por su parte, el Auto Acordado "Normas sobre lobby, registros públicos con fines de transparencia, imparcialidad, independencia y publicidad" del 30 de diciembre de 2014, en su artículo 39, establece, de forma general, que una de las formas de intervención de "terceros ajenos al litigio" es a través de la AP. En su artículo 37, señala que son terceros ajenos al litigio las "personas naturales o jurídicas, agrupaciones o entidades, que tengan algún interés vinculado con la resolución del proceso, que no sean partes directas o indirectas en él ni tampoco detenten la calidad de órganos constitucionales interesados. Así, se consideran terceros, entre otros, los organismos públicos, las universidades, los centros de estudios, los académicos, las organizaciones no gubernamentales, fundaciones, juntas de vecinos y otras entidades análogas".

El artículo citado dispone, además, que el tribunal convocará a una AP en aquellos casos en que, conforme con el artículo 37 de la LOCTC, lo estime necesario para una mejor resolución del asunto. Agrega que se procederá a fijar AP, especialmente, en los casos del artículo 93, numerales 7 y 16, de la Constitución Política de la República, correspondientes a la acción de inconstitucionalidad de la ley y al control de constitucionalidad de decretos supremos, respectivamente. Así mismo, determina que para participar en dicha audiencia el interesado deberá registrarse en la forma en que se indique por la resolución que el tribunal dicte al efecto.

Como se observa, no existe una regulación que defina las audiencias, requisitos de los participantes, objetivo de la convocatoria, ritualidad de la audiencia, etc. Estos dependen de lo que disponga, en cada caso, la resolución que haga el llamado. De la revisión de las resoluciones que han convocado a audiencias, aparece que el tribunal utiliza una fórmula tipo, que reza: "Que esta magistratura estima que puede contribuir a la mejor resolución de este proceso constitucional el oír también a aquellas instituciones y organizaciones representativas de los intereses involucrados en el asunto que debe resolver este tribunal, que deseen acompañar información y/o exponer sobre la materia jurídicoconstitucional de autos".13

13 Solo en una causa, Rol 2800-2015, en materia de inconstitucionalidad del artículo $5^{\circ}$ de la Ley de Ahorros del Antiguo Sistema Nacional de Ahorro y Préstamo, se agrega a la fórmula antes señalada la expresión "contando con información especializada en la materia 
En definitiva, el tribunal llamará a AP a su discreción, y los requisitos para admitirse a una persona $u$ organización a las audiencias dependen exclusivamente de la resolución que convoca, que por regla general solo exigen tener un interés involucrado en el asunto. Así, no es posible identificar un perfil claro en cuanto a qué intereses deben tener voz en los procesos de control de constitucionalidad, ni tampoco qué tipo de argumentos o antecedentes espera recibir el TCCh de la sociedad civil para "la mejor resolución del asunto".

\section{Análisis de las audiencias públicas convocadas por el Tribunal Constitucional chileno}

Para comprender esta herramienta nueva, que se inserta dentro del proceso de control de constitucionalidad, es necesario considerar a las AP públicas como un continuo, que se despliega en distintos momentos a lo largo del proceso (Benedetti \& Sáenz, 2018, p. 105). No solo debe observarse la realización de la audiencia misma y su ritualidad procesal, sino también los momentos previos a esta, cuando se seleccionan los casos en que se convocarán las audiencias, y se define a quiénes se oirá. Debe también observarse el momento posterior a su realización, es decir, el impacto que tiene la audiencia en el momento de la decisión del caso. En este trabajo nos concentramos en dos momentos de las AP: el momento previo a la audiencia, de la selección de los casos en que se convocan, y el momento final de la sentencia.

El universo de casos analizados se constituye por la totalidad de las causas en que se convocó a AP por el TCCh durante el período comprendido entre los años 2007 a 2018. El año 2007 se convoca a la primera AP, en materia de píldora de anticoncepción de emergencia, mientras que la última audiencia analizada en este trabajo es la realizada en el año 2018 a propósito de los requisitos para la concesión de libertades condicionales a personas condenadas por delitos de lesa humanidad. Se analizaron 18 AP realizadas, que dan cuenta de más de una década de

de autos". Llama la atención que se trata de una de las audiencias que menor interés y participación concitó, participando solo una universidad en la audiencia convocada. 
práctica de convocatorias a esta forma de participación de la sociedad civil ante la jurisdicción constitucional.

\section{Momento previo a la audiencia: la selección de los casos}

Para comprender cabalmente a las AP, es necesario identificar en qué casos y con qué criterios se decide convocarlas. Con este objetivo, analizamos en ejercicio de qué atribuciones de control de constitucionalidad el TCCh ha convocado a AP, y las materias sustantivas en que se ha hecho uso de esta herramienta de participación. La relevancia de evaluar las materias y la lógica con que se ha convocado a AP radica en que las audiencias evidencian cuáles son las prioridades del tribunal y construyen un perfil institucional de cara a la ciudadanía (Benedetti E Sáenz, 2018, p. 104).

Del análisis de las 18 audiencias estudiadas, es posible observar que se han convocado en procesos de control de constitucionalidad en ejercicio de las siguientes atribuciones: control preventivo facultativo de proyectos de ley (art. 93, num. 3); control preventivo facultativo de constitucionalidad de tratados internacionales (art. 93, num. 3); acción de inconstitucionalidad iniciada de oficio y por acción pública (art. 93, num. 7); y control de constitucionalidad de los decretos supremos (art. 93, num. 16).

Tabla 1. Causas en las que se convocaron audiencias públicas 2007-2018

\begin{tabular}{|c|c|l|l|}
\hline$N^{\boldsymbol{o}}$ & \multicolumn{1}{|c|}{ Mol } & \multicolumn{1}{|c|}{ Materia } & $\begin{array}{l}\text { Causal por la cual está conociendo } \\
\text { el Tribunal Constitucional }\end{array}$ \\
\hline 1 & $740-2007$ & $\begin{array}{l}\text { Normas nacionales sobre regulación } \\
\text { de la fertilidad }\end{array}$ & $\begin{array}{l}\text { Control de decreto supremo } \\
\text { artículo 93, numeral 16 }\end{array}$ \\
\hline 2 & $1710-10$ & $\begin{array}{l}\text { Artículo 38 ter de la Ley 18933 } \\
\text { de Isapres }\end{array}$ & $\begin{array}{l}\text { Acción de inconstitucionalidad } \\
93, \text { numeral 7 }\end{array}$ \\
\hline 3 & $1723-10$ & $\begin{array}{l}\text { Daño moral por imputaciones } \\
\text { injuriosas, artículo 2331 del } \\
\text { Código Civil }\end{array}$ & $\begin{array}{l}\text { Acción de inconstitucionalidad } \\
93, \text { numeral 7 }\end{array}$ \\
\hline 4 & $1988-11$ & $\begin{array}{l}\text { Convenio Internacional para la } \\
\text { Protección de Obtenciones Vege- } \\
\text { tales (UPOV-91) }\end{array}$ & $\begin{array}{l}\text { Control preventivo facultativo } \\
\text { de tratados internacionales 93, } \\
\text { numeral 3 }\end{array}$ \\
\hline
\end{tabular}




\begin{tabular}{|c|c|c|c|}
\hline$N^{o}$ & Rol & Materia & $\begin{array}{c}\text { Causal por la cual está conociendo } \\
\text { el Tribunal Constitucional }\end{array}$ \\
\hline 5 & 2081-11 & $\begin{array}{l}\text { Filiación hijo póstumo, artículo } \\
206 \text { del Código Civil }\end{array}$ & $\begin{array}{l}\text { Acción de inconstitucionalidad } \\
\text { 93, numeral } 7\end{array}$ \\
\hline 6 & $2358-12$ & $\begin{array}{l}\text { Introducción de la televisión digital } \\
\text { terrestre }\end{array}$ & $\begin{array}{l}\text { Control preventivo facultativo } \\
\text { proyecto de ley artículo 93, } \\
\text { numeral } 3\end{array}$ \\
\hline 7 & $2386-12$ & $\begin{array}{l}\text { Modificación en el ámbito de la } \\
\text { sustentabilidad de recursos hidro- } \\
\text { biológicos, acceso a la actividad } \\
\text { pesquera industrial y artesanal, y } \\
\text { regulaciones para la investigación } \\
\text { y fiscalización }\end{array}$ & $\begin{array}{l}\text { Control preventivo facultativo } \\
\text { proyecto de ley artículo 93, } \\
\text { numeral } 3\end{array}$ \\
\hline 8 & $2387-12$ & $\begin{array}{l}\text { Modificación en el ámbito de la } \\
\text { sustentabilidad de recursos hidro- } \\
\text { biológicos, acceso a la actividad } \\
\text { pesquera industrial y artesanal, y } \\
\text { regulaciones para la investigación } \\
\text { y fiscalización }\end{array}$ & $\begin{array}{l}\text { Control preventivo facultativo } \\
\text { proyecto de ley artículo 93, } \\
\text { numeral } 3\end{array}$ \\
\hline 9 & $2388-12$ & $\begin{array}{l}\text { Modificación en el ámbito de la } \\
\text { sustentabilidad de recursos hidro- } \\
\text { biológicos, acceso a la actividad } \\
\text { pesquera industrial y artesanal, y } \\
\text { regulaciones para la investigación } \\
\text { y fiscalización }\end{array}$ & $\begin{array}{l}\text { Control preventivo facultativo } \\
\text { proyecto de ley artículo 93, } \\
\text { numeral } 3\end{array}$ \\
\hline 10 & $2541-13$ & $\begin{array}{l}\text { Introducción de la televisión digi- } \\
\text { tal terrestre }\end{array}$ & $\begin{array}{l}\text { Control preventivo facultativo } \\
\text { proyecto de ley artículo 93, } \\
\text { numeral } 3\end{array}$ \\
\hline 11 & $2565-13$ & $\begin{array}{l}\text { Manifestación expresa de la acep- } \\
\text { tación del consumidor en contra- } \\
\text { tos de adhesión de productos y } \\
\text { servicios financieros }\end{array}$ & $\begin{array}{l}\text { Control de decreto supremo } \\
\text { artículo 93, numeral } 16\end{array}$ \\
\hline 12 & $2777-15$ & $\begin{array}{l}\text { Sustitución del sistema electoral } \\
\text { binominal por uno de carácter } \\
\text { proporcional inclusivo y fortaleci- } \\
\text { miento de la representatividad del } \\
\text { Congreso Nacional }\end{array}$ & $\begin{array}{l}\text { Control preventivo facultativo } \\
\text { proyecto de ley artículo 93, } \\
\text { numeral } 3\end{array}$ \\
\hline 13 & $2787-15$ & $\begin{array}{l}\text { Regulación de la admisión de } \\
\text { los y las estudiantes, eliminación } \\
\text { del financiamiento compartido y } \\
\text { prohibición del lucro en estableci- } \\
\text { mientos educacionales que reci- } \\
\text { ben aportes del Estado }\end{array}$ & $\begin{array}{l}\text { Control preventivo facultativo } \\
\text { proyecto de ley artículo 93, } \\
\text { numeral } 3\end{array}$ \\
\hline
\end{tabular}




\begin{tabular}{|c|c|c|c|}
\hline$N^{o}$ & Rol & Materia & $\begin{array}{c}\text { Causal por la cual está conociendo } \\
\text { el Tribunal Constitucional }\end{array}$ \\
\hline 14 & $2800-15$ & $\begin{array}{l}\text { Inconstitucionalidad del artículo } \\
5^{\circ} \text { de la Ley de Ahorros del Anti- } \\
\text { guo Sistema Nacional de Ahorro } \\
\text { y Préstamo }\end{array}$ & $\begin{array}{l}\text { Acción de inconstitucionalidad } \\
\text { 93, numeral } 7\end{array}$ \\
\hline 15 & $2935-15$ & $\begin{array}{l}\text { Proyecto de Ley de Presupuestos } \\
\text { del Sector Público (glosa gratui- } \\
\text { dad) }\end{array}$ & $\begin{array}{l}\text { Control preventivo facultativo } \\
\text { proyecto de ley artículo 93, } \\
\text { numeral } 3\end{array}$ \\
\hline 16 & $3016-16$ & $\begin{array}{l}\text { Modernización del sistema de } \\
\text { relaciones laborales }\end{array}$ & $\begin{array}{l}\text { Control preventivo facultativo } \\
\text { proyecto de ley artículo 93, } \\
\text { numeral } 3\end{array}$ \\
\hline 17 & $3729-17$ & $\begin{array}{l}\text { Regulación de la despenalización } \\
\text { de la interrupción voluntaria del } \\
\text { embarazo en tres causales }\end{array}$ & $\begin{array}{l}\text { Control preventivo facultativo } \\
\text { proyecto de ley artículo 93, } \\
\text { numeral } 3\end{array}$ \\
\hline 18 & $\begin{array}{c}5677- \\
18 / 5678-18 \\
\text { (acumuladas) }\end{array}$ & $\begin{array}{l}\text { Sustitución del decreto-ley que } \\
\text { establece la libertad condicional } \\
\text { para los penados }\end{array}$ & $\begin{array}{l}\text { Control preventivo facultativo } \\
\text { proyecto de ley artículo 93, } \\
\text { numeral } 3\end{array}$ \\
\hline
\end{tabular}

Fuente: elaboración de los autores.

Como se observa en la tabla 1, el TCCh ha considerado de utilidad para mejor resolver el asunto de que conoce convocar a audiencias en ejercicio de su competencia de control preventivo facultativo de control de constitucionalidad de proyectos de ley (93, num. 3). De las 18 audiencias que se analizaron, 11 se referían a esta atribución, lo que corresponde a un $61 \%$ de las audiencias convocadas.

\section{Figura 1. Competencia por la cual el TCCh convoca a audiencias públicas}

Control preventivo facultativo de proyectos de ley art. 93, num. 3

Control preventivo facultativo de tratados internacionales art. 93, num. 3

Control de Decreto Supremo art. 93, num. 16

Acción de inconstitucionalidad art. 93, num. 17

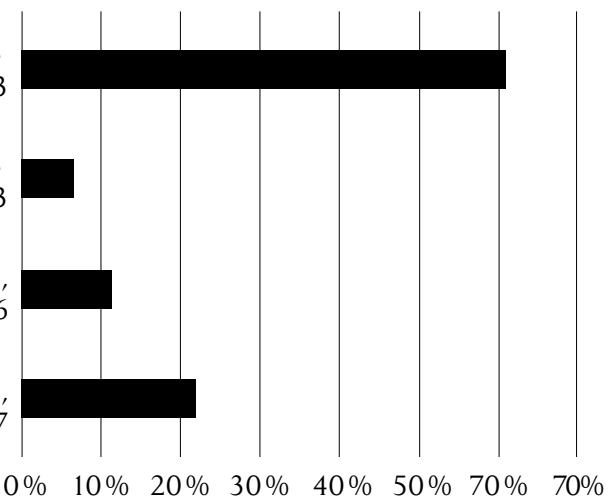

Fuente: elaboración de los autores. 
Este hallazgo es interesante, ya que los procesos de control preventivo de constitucionalidad suelen tener un alto perfil público, al tiempo que se hace ejercicio de una atribución que ha suscitado críticas de la doctrina por su elevada politicidad. ${ }^{14}$ Una explicación posible sería que, a través de la convocatoria a AP en este tipo de causas, el TCCh busca aumentar la legitimidad de su decisión para hacer frente a previsibles cuestionamientos de su carácter político. Sin embargo, no se han convocado audiencias en materia de control preventivo obligatorio, también una atribución altamente cuestionada por su politicidad y el controvertido carácter de 'tercera cámara' del TCCh. ${ }^{15}$ Luego, los datos podrían llevar a concluir que se busca convocar a AP para fortalecer la legitimidad de la decisión. No obstante, la ausencia de AP en causas de control de constitucionalidad preventivo obligatorio introduce dudas a este respecto y no es posible ser concluyentes en este punto.

Otra cuestión que llama la atención es que las audiencias convocadas no son siempre coherentes con lo dispuesto por el auto acordado. Este dispone que las AP se convocarán especialmente cuando el tribunal conozca de la acción de inconstitucionalidad (art. 93, num. 7) y del control de constitucionalidad de decretos supremos (art. 93, num. 16). Sin embargo, en los hechos, de las 18 audiencias realizadas en el período analizado, solo 6 corresponden al ejercicio de las atribuciones indicadas (4 de acción de inconstitucionalidad y 2 de decretos supremos). ${ }^{16}$ Es así

14 En tal sentido, Ahumada (2018, p. 404) y Grupo de Estudio de Reforma al Tribunal Constitucional (2019, pp. 7-8). Señala el documento del Grupo de Estudio de Reforma al Tcch que "el defecto reconocido del control preventivo es que queda muy cerca de la política y del proceso de factura de la ley. Es la continuación de la política partidista, pero por 'otros medios', lo que tiende a contaminar al TC con las tensiones propias del proceso político" (Grupo de Estudio de Reforma al Tribunal Constitucional, 2019, p. 13).

15 El término de 'tercera cámara' se ha popularizado en la discusión pública chilena para hacer referencia de un modo peyorativo a la politicidad del control de constitucionalidad que ejerce el tribunal y que permitiría trasladar el debate político desde el Congreso Nacional hacia una 'tercera cámara legislativa' (el TCCh). En este sentido se pronuncia Bassa cuando enuncia: "Así, si la composición del Tribunal refleja fielmente la correlación de fuerzas políticas al interior del Congreso Nacional, lo más probable es que cada vez que la minoría parlamentaria recurra al TC, obtendrá una resolución contraria a sus intereses; no sería más que una tercera cámara legislativa" (2015, p. 265).

16 Se toma el universo total de audiencias desde 2017 a 2018; sin embargo, la observación también es aplicable a las AP convocadas con posterioridad a la fecha de publicación del auto acordado. 
como puede concluirse que el Tribunal Constitucional no respeta la reglamentación que él mismo ha dispuesto. ${ }^{17}$

También destaca que, pese a que la mayoría de las causas que conoce el TCCh son acciones de inaplicabilidad por inconstitucionalidad ${ }^{18}$ (control concreto), la totalidad de las causas en que se ha utilizado la herramienta de las AP corresponde a controles abstractos de constitucionalidad.

En cuanto a las materias sustantivas respecto de las cuales han versado los procesos en que se ha convocado a AP, no es posible identificar un perfil claro. Se ha llamado a audiencias en materias tan disímiles como anticoncepción de emergencia, determinación de filiación del hijo póstumo, reforma laboral, reforma educacional, etc.

Tabla 2. Materias en las que se ha convocado a audiencias públicas

\begin{tabular}{|c|c|c|c|}
\hline$N^{o}$ & Rol & Materia & Nombre caso \\
\hline 1 & $740-2007$ & Normas nacionales sobre regulación de la fertilidad & Píldora \\
\hline 2 & $1710-10$ & Artículo 38 ter de la Ley 18933 de Isapres & Isapres \\
\hline 3 & $1723-10$ & $\begin{array}{l}\text { Daño moral por imputaciones injuriosas, artículo } \\
2331 \text { del Código Civil }\end{array}$ & Daño moral \\
\hline 4 & 1988-11 & $\begin{array}{l}\text { Convenio Internacional para la Protección de } \\
\text { Obtenciones Vegetales (UPOV-91) }\end{array}$ & Semillas \\
\hline 5 & $2081-11$ & $\begin{array}{l}\text { Filiación hijo póstumo, artículo } 206 \text { del Código } \\
\text { Civil }\end{array}$ & Hijo póstumo \\
\hline 6 & $2358-12$ & Introducción de la televisión digital terrestre & TV digital 1 \\
\hline 7 & $2386-12$ & $\begin{array}{l}\text { Modificación en el ámbito de la sustentabilidad } \\
\text { de recursos hidrobiológicos, acceso a la actividad } \\
\text { pesquera industrial y artesanal, y regulaciones } \\
\text { para la investigación y fiscalización }\end{array}$ & Ley de Pesca 1 \\
\hline
\end{tabular}

17 Esto también se demuestra porque, de las resoluciones que convocan a AP, solo en una de las 18 se hace referencia al auto acordado. Es más, el artículo 40 del auto acordado establece que existirá un registro público de la intervención de 'terceros ajenos al litigio' que pueden intervenir, según el mismo auto acordado, a través de las AP por medio de presentaciones escritas, que se encontrará disponible en el sitio web www.tribunalconstitucional.cl. Este registro no existe.

18 A modo de ejemplo, en el año 2018, de los 1663 asuntos ingresados al TCCh, 1618 corresponden a acciones de inaplicabilidad por inconstitucionalidad (véase: https://www. tribunalconstitucional.cl/estadisticas/estadisticas-ano-2017). 


\begin{tabular}{|c|c|c|c|}
\hline$N^{o}$ & Rol & Materia & Nombre caso \\
\hline 8 & $2387-12$ & $\begin{array}{l}\text { Modificación en el ámbito de la sustentabilidad } \\
\text { de recursos hidrobiológicos, acceso a la actividad } \\
\text { pesquera industrial y artesanal, y regulaciones } \\
\text { para la investigación y fiscalización }\end{array}$ & Ley de Pesca 2 \\
\hline 9 & $2388-12$ & $\begin{array}{l}\text { Modificación en el ámbito de la sustentabilidad } \\
\text { de recursos hidrobiológicos, acceso a la actividad } \\
\text { pesquera industrial y artesanal, y regulaciones } \\
\text { para la investigación y fiscalización }\end{array}$ & Ley de Pesca 3 \\
\hline 10 & $2541-13$ & Introducción de la televisión digital terrestre & TV digital 2 \\
\hline 11 & $2565-13$ & $\begin{array}{l}\text { Manifestación expresa de la aceptación del con- } \\
\text { sumidor en contratos de adhesión de productos y } \\
\text { servicios financieros }\end{array}$ & $\begin{array}{l}\text { Contratos de } \\
\text { adhesión }\end{array}$ \\
\hline 12 & $2777-15$ & $\begin{array}{l}\text { Sustitución del sistema electoral binominal por } \\
\text { uno de carácter proporcional inclusivo y forta- } \\
\text { lecimiento de la representatividad del Congreso } \\
\text { Nacional }\end{array}$ & Binominal \\
\hline 13 & $2787-15$ & $\begin{array}{l}\text { Regulación de la admisión de los y las estudian- } \\
\text { tes, eliminación del financiamiento compartido y } \\
\text { prohibición del lucro en establecimientos educa- } \\
\text { cionales que reciben aportes del Estado }\end{array}$ & $\begin{array}{l}\text { Reforma } \\
\text { educacional }\end{array}$ \\
\hline 14 & $2800-15$ & $\begin{array}{l}\text { Inconstitucionalidad del artículo } 5^{\circ} \text { de la Ley de } \\
\text { Ahorros del Antiguo Sistema Nacional de Ahorro } \\
\text { y Préstamo }\end{array}$ & $\begin{array}{l}\text { Ahorro y } \\
\text { préstamo }\end{array}$ \\
\hline 15 & $2935-15$ & $\begin{array}{l}\text { Proyecto de Ley de Presupuestos del Sector } \\
\text { Público (glosa gratuidad) }\end{array}$ & Glosa gratuidad \\
\hline 16 & $3016-16$ & Modernización del sistema de relaciones laborales & Reforma laboral \\
\hline 17 & $3729-17$ & $\begin{array}{l}\text { Regulación de la despenalización de la interrup- } \\
\text { ción voluntaria del embarazo en tres causales }\end{array}$ & $\begin{array}{l}\text { Aborto tres } \\
\text { causales }\end{array}$ \\
\hline 18 & $\begin{array}{c}5677- \\
18 / 5678-18 \\
\text { (acumuladas) }\end{array}$ & $\begin{array}{l}\text { Sustitución del decreto-ley que establece la liber- } \\
\text { tad condicional para los penados }\end{array}$ & $\begin{array}{l}\text { Libertades condi- } \\
\text { cionales }\end{array}$ \\
\hline
\end{tabular}

Fuente: elaboración de los autores.

A pesar de que la teoría y la práctica indican que los casos en que se convoca a la participación de la sociedad civil son de alta connotación política, como lo fueron las audiencias en materia de libertades condicionales de condenados por delitos de lesa humanidad, despenalización del aborto en tres causales o la prohibición del lucro en la educación, también hay una cantidad no despreciable de casos en que se convocó a 
audiencias en materias en que no hubo una cantidad importante de solicitudes de ser oídos. Un ejemplo es el caso del Sistema Nacional de Ahorro y Préstamo, que no tuvo repercusión pública ninguna y en la que solo participó una organización. Como se observa, las materias en las que se ha llamado a audiencias son tan dispares que no es posible identificar un criterio uniforme, o elaborar taxonomías a su respecto. A partir de estos datos no es posible dar luces sobre la autocomprensión del TCCh respecto de su rol en el sistema democrático, o si existe un perfil público que busca cultivar. Lo errático de las materias en que se convoca a audiencias no resulta inocuo: la ausencia de criterios reconocibles puede ser indicio de un ejercicio arbitrario de esta facultad. Sobre todo, desde que en ocasiones se ha solicitado al tribunal que se convoque a AP en materias de alto interés político y público, y dichas peticiones no han sido acogidas, ${ }^{19}$ sin que se hayan dictado resoluciones que fundamenten dicha negativa. Simplemente, las audiencias no fueron convocadas.

Resumiendo, el TCCh a la hora de convocar a AP no lo hace con un criterio uniforme, debido a la materia que se encuentra sometida a su conocimiento, sino que la selección de causas se vincula estrechamente con la atribución ejercida, concentrándose las convocatorias en causas relativas a control preventivo facultativo de proyectos de ley.

\section{Momento posterior a la audiencia: la sentencia}

Para saber si la participación de la sociedad civil en la AP que se ha convocado dentro del proceso ha implicado un enriquecimiento de la deliberación de los jueces constitucionales, resulta imprescindible analizar el momento de la decisión del caso, que se concreta en la sentencia que lo resuelve y, particularmente, en sus fundamentos. El análisis de estos permitirá determinar si de la realización de las audiencias se ha seguido

19 A modo de ejemplo, es el caso de las causas Rol 8792-20 (art. 93, num. 6), relativa a disposiciones que permiten bajar las penas respecto de delitos sexuales cometidos en Rapa Nui; Rol 4757-18, sobre requerimiento de inconstitucionalidad que establece visto consular de turismo a nacionales de Haití (art. 93, num. 7); y Rol 3687-17, sobre control de constitucionalidad del proyecto de ley que crea la XVI Región de Nuble (art. 93, num. 1). 
una apertura del razonamiento judicial a los antecedentes, argumentaciones e interpretaciones que aportaron los participantes de las AP.

La obligación de fundamentar las sentencias del TCCh se encuentra en el artículo 39 de la LOCTC. Esta disposición reenvía al artículo 170 del Código de Procedimiento Civil, que al establecer las disposiciones comunes a todo procedimiento señala los requisitos que deben cumplir las sentencias definitivas en sus numerales 1 a 6 , esto es, la designación precisa de las partes litigantes, su domicilio y profesión u oficio; la enunciación breve de las peticiones o acciones deducidas por el demandante y de sus fundamentos; igual enunciación de las excepciones o defensas alegadas por el demandado; las consideraciones de hecho o de derecho que sirven de fundamento a la sentencia; la enunciación de las leyes, y en su defecto de los principios de equidad, con arreglo a los cuales se pronuncia el fallo; y la decisión del asunto controvertido. Luego, no existe obligación de hacer referencia a las AP en la sentencia de constitucionalidad. No obstante, si los jueces constitucionales han recogido los elementos y argumentaciones proporcionados en las AP, estos podrían quedar comprendidos dentro del numeral 4 del artículo 170, que indica que el fallo ha de contener "las consideraciones de hecho o de derecho que sirven de fundamento a la sentencia".

En este trabajo se analizaron 18 de las causas en que se convocó a AP, de las cuales 17 terminaron con sentencia definitiva. ${ }^{20}$ Utilizando un método textualista, similar a los estudios realizados en los casos argentino y brasilero, se identificaron las referencias expresas a las audiencias en la sentencia, tanto en sus votos de mayoría como particulares. No se analizaron los argumentos de fondo vertidos en las audiencias que pudieran haberse recogido en los fallos sin explicitarlo, por las dificultades metodológicas que esto implicaría.

De los 17 fallos analizados, 11 de ellos solo hacen referencia a la realización de la audiencia en su parte expositiva, sin que se haga mención en la parte considerativa de la sentencia o en los votos particulares. Es decir, en el $64,7 \%$ de las causas en que se realizó una AP esta no tuvo ningún impacto en la argumentación de la decisión, ni en el voto

20 La Causa Rol 2565-2013 terminó por desistimiento. 
de mayoría, ni en los votos particulares. En las seis sentencias restantes $(35,3 \%)$, la parte considerativa del fallo mencionó la realización de AP.

Figura 2. Referencias a las audiencias públicas en las sentencias

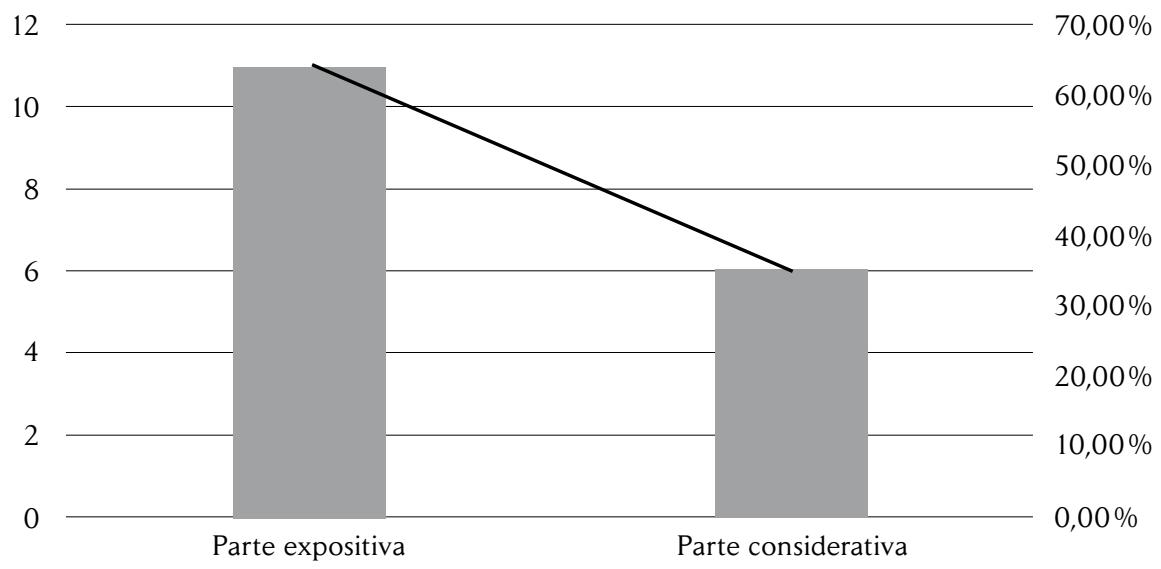

Fuente: elaboración de los autores.

Respecto de las sentencias en que sí se hizo referencia a las AP en la parte considerativa del fallo, se estudiaron todas las menciones realizadas, ya sea en el voto mayoritario, ya sea en los votos particulares, concurrentes o disidentes. En cuanto a estas referencias expresas nos formulamos las siguientes preguntas: i) ¿qué rol cumple la referencia a la audiencia en la argumentación de la sentencia?; ii) ¿la mención a la audiencia se encuentra en el voto mayoritario o en votos particulares?; y iii) ¿qué control de constitucionalidad o atribución se ejercía en la causa que resuelve el fallo que menciona a las audiencias?

\section{Rol que cumplen las referencias a las audiencias públicas en la argumentación de la sentencia}

El estudio de las sentencias y el contexto de la argumentación en que se realizaron las menciones expresas a las audiencias permitieron identificar diversas categorías de usos argumentativos de dichas menciones, según la función que cumplen dentro de la fundamentación del fallo.

Proponemos la siguiente taxonomía de usos o roles de las referencias a las AP: a) incorporación de elementos técnicos; b) incorporación de 
elementos fácticos; c) incorporación de argumentos jurídicos planteados por participantes; d) reforzamiento del argumento jurídico del redactor; y e) mención meramente ilustrativa del desarrollo del proceso.

El uso (a) significa que la referencia a la AP incorpora a la argumentación de la sentencia una cuestión técnica que fue expresada en las AP y que el TCch no conocía, o que necesitaba reforzar. ${ }^{21}$

El uso (b) indica que la referencia a la AP incorpora a la argumentación de la sentencia una cuestión de hecho o antecedente fáctico que fue señalado en las AP y que el TCCh no conocía, o que necesitaba reforzar.

El uso (c) alude a que en la sentencia se hace referencia expresa a un argumento jurídico sobre la interpretación constitucional que ha sido planteado por los participantes en las AP. En este caso existe un argumento jurídico que aparece en la AP y que se recoge por los jueces constitucionales como argumento en la sentencia, sea para fundar la decisión, sea para hacerse cargo del argumento y controvertirlo. Este uso es el más interesante desde un punto de vista conceptual, puesto que reconoce que la sociedad civil también es un intérprete de la Constitución.

El uso (d) implica que la referencia de la sentencia a la AP se realiza para apoyar el argumento que viene siendo expresado por los jueces constitucionales que redactaron la sentencia (o el voto particular). Se trata de una función de refuerzo, a mayor abundamiento, del razonamiento de el o los ministros. Se diferencia del uso (c) porque no incorpora 'desde fuera' el argumento jurídico, sino que este estaba ya en la argumentación del tribunal.

Finalmente, el uso (e) simplemente menciona la AP en la sentencia a modo ilustrativo, describiendo el modo en que se desarrolló el proceso, pero sin una función argumentativa definida.

En este punto es necesario volver sobre lo dicho en cuanto a la identificación de los objetivos de la convocatoria a AP. Como explicamos, coexisten dos objetivos institucionales, uno de orden técnico o fáctico (enriquecer la deliberación aportando antecedentes que, por su naturaleza de conocimiento técnico o fáctico, están fuera de la expertise y alcance de

21 Por cuestión técnica nos referimos a conocimientos de disciplinas diversas al derecho, como pudiera ser información médica o científica. Es el caso de la información relativa a la concepción y reproducción humana que se entregó por médicos en las causas 'píldora' y 'aborto tres causales'. 
los jueces constitucionales) y otro de orden normativo (democratización del proceso al potenciar la deliberación y dar voz en la interpretación constitucional a actores no institucionales o estatales). Los hallazgos de la investigación en relación con los usos argumentativos de las referencias a las AP en las sentencias confirman la coexistencia de dichos objetivos.

Los usos (a) y (b) se relacionan con el objetivo técnico o fáctico. Serían un insumo que viene a complementar el conocimiento no jurídico de los ministros. Su función es ilustrar a la jurisdicción constitucional, incorporando a la discusión antecedentes útiles o necesarios para la resolución del asunto que son ajenos a la expertise o ámbito de conocimiento de los jueces constitucionales.

Por su parte, los usos (c) y (d) se relacionan con el objetivo normativo de enriquecer la deliberación del TCCh, al ampliar y democratizar la interpretación constitucional. Estos usos permiten que otros actores, más allá de las partes y los jueces constitucionales, colaboren en el proceso de determinación del significado de la Constitución. De estos, el uso más relevante es el (c), porque extrae ese significado desde la sociedad civil. Es el uso en que realmente se produce la concreción de la interpretación abierta de la Constitución (Häberle, 2008).

Figura 3. Frecuencias de usos de las referencias de las audiencias públicas en la sentencia

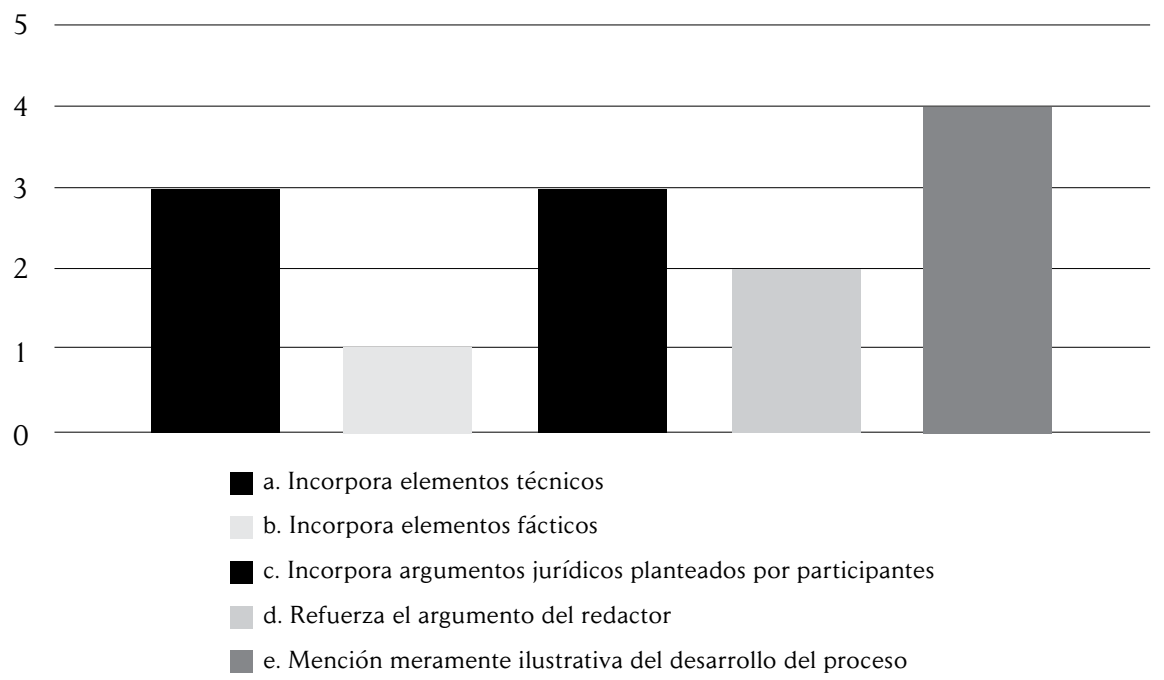

Fuente: elaboración de los autores. 
Finalmente, el uso (e) es neutro, ya que no impacta ni en ampliar los insumos requeridos por el TCCh para deliberar, ni incorpora ni utiliza argumentos jurídicos que provengan 'desde fuera' del proceso de control de constitucionalidad.

Como se aprecia, las referencias a las AP se usan de un modo más o menos equilibrado para tomar elementos jurídicos o fácticos/técnicos, sin que un objetivo sea más relevante que otro.

\section{Frecuencia de las referencias a las audiencias públicas en los votos de mayoría y votos particulares}

En las seis sentencias que hacen referencia a las AP en su argumentación, se identificó si la mención estaba en el voto mayoritario o en un voto particular disidente o concurrente, o en ambas partes.

Tabla 3. Referencia a las audiencias públicas en los votos de la mayoría y uso argumentativo de la mención

\begin{tabular}{|l|c|c|c|c|c|c|}
\hline \multicolumn{1}{|c|}{ Materia } & $\begin{array}{c}\text { Refe- } \\
\text { rencia }\end{array}$ & $\begin{array}{c}\text { a) Incor- } \\
\text { pora ele- } \\
\text { mentos } \\
\text { técnicos }\end{array}$ & $\begin{array}{c}\text { b) Incor- } \\
\text { pora ele- } \\
\text { mentos } \\
\text { fácticos }\end{array}$ & $\begin{array}{c}\text { c) Incorpora } \\
\text { argumentos } \\
\text { jurídicos } \\
\text { planteados por } \\
\text { participantes }\end{array}$ & $\begin{array}{c}\text { d) Re- } \\
\text { fuerza } \\
\text { el argu- } \\
\text { mento del } \\
\text { redactor }\end{array}$ & $\begin{array}{c}\text { e) Mención } \\
\text { meramente } \\
\text { ilustrativa } \\
\text { del desarrollo } \\
\text { del proceso }\end{array}$ \\
\hline Aborto tres causales & Sí & Sí & Sí & & & Sí \\
\hline Semillas & Sí & & & Sí & & \\
\hline Reforma laboral & No & & & & & \\
\hline Píldora & Sí & Sí & & & & \\
\hline Daño moral & No & & & & & \\
\hline Libertades condicio- & Sí & & & Sí & & \\
nales & & & & & \\
\hline
\end{tabular}

Fuente: elaboración de los autores.

Como se aprecia en la tabla 3, de los seis casos en que se menciona a las AP, estas son valoradas en votos de mayoría en cuatro causas, relativas a las materias de 'aborto tres causales', 'semillas', 'píldora' y 'libertades condicionales'. No se hace referencia en el voto de la mayoría en los casos de reforma laboral y daño moral. 
En los votos de mayoría, los usos que se les dan a las referencias a las AP son todas las categorías identificadas, excepto la forma 'd', que implica utilizar las argumentaciones de la audiencia como refuerzo de su propia posición, la cual solo se utiliza cuando la referencia es en un voto minoritario.

Tabla 4. Referencia a las audiencias públicas en los votos de la minoría y uso argumentativo de la mención

\begin{tabular}{|l|c|c|c|c|c|c|}
\hline \multicolumn{1}{|c|}{ Materia } & $\begin{array}{c}\text { Refe- } \\
\text { rencia }\end{array}$ & $\begin{array}{c}\text { a) Incor- } \\
\text { pora ele- } \\
\text { mentos } \\
\text { técnicos }\end{array}$ & $\begin{array}{c}\text { b) Incor- } \\
\text { pora ele- } \\
\text { mentos } \\
\text { fácticos }\end{array}$ & $\begin{array}{c}\text { c) Incorpora } \\
\text { argumentos } \\
\text { jurídicos } \\
\text { planteados por } \\
\text { participantes }\end{array}$ & $\begin{array}{c}\text { d) Re- } \\
\text { fuerza } \\
\text { el argu- } \\
\text { mento del } \\
\text { redactor }\end{array}$ & $\begin{array}{c}\text { e) Mención } \\
\text { meramente } \\
\text { ilustrativa } \\
\text { del desarrollo } \\
\text { del proceso }\end{array}$ \\
\hline Aborto tres causales & Sí & Sí & Sí & Sí & Sí & Sí \\
\hline Semillas & Sí & & & Sí & & Sí \\
\hline Reforma laboral & Sí & Sí & & & Sí & \\
\hline Píldora & Sí & Sí & & & & Sí \\
\hline Daño moral & No & & & & & \\
\hline $\begin{array}{l}\text { Libertades condicio- } \\
\text { nales }\end{array}$ & No & & & & & \\
\hline
\end{tabular}

Fuente: elaboración de los autores.

En cambio, en los votos disidentes, es posible identificar que también se hizo referencia a las AP en cuatro causas ('aborto tres causales', 'semillas', 'reforma laboral' y 'píldora'); no obstante, se argumentó empleando todos los usos argumentativos de la mención que se categorizan en el presente estudio.

Así, resulta llamativo que el caso aborto tres causales es la única causa de todo el universo analizado en que se incorporaron elementos técnicos, fácticos, argumentos jurídicos planteados por los participantes, se reforzó el argumento del redactor y se hizo una mención meramente ilustrativa del desarrollo del proceso.

En el caso de los votos concurrentes, solo se puede identificar una referencia y un uso dentro de la categorización efectuada, que corresponde a una mención meramente ilustrativa del desarrollo del proceso, por cuanto desde ya es posible señalar que para la redacción de los votos concurrentes las AP parecen ser irrelevantes. 
Tabla 5. Referencia a las audiencias públicas en los votos concurrentes y uso argumentativo de la mención

\begin{tabular}{|l|c|l|l|l|l|l|}
\hline \multicolumn{1}{|c|}{ Materia } & $\begin{array}{c}\text { Refe- } \\
\text { rencia }\end{array}$ & $\begin{array}{c}\text { a) Incor- } \\
\text { pora ele- } \\
\text { mentos } \\
\text { técnicos }\end{array}$ & $\begin{array}{c}\text { b) Incor- } \\
\text { pora ele- } \\
\text { mentos } \\
\text { fácticos }\end{array}$ & $\begin{array}{c}\text { c) Incorpora } \\
\text { argumentos } \\
\text { jurídicos } \\
\text { planteados por } \\
\text { participantes }\end{array}$ & $\begin{array}{c}\text { d) Re- } \\
\text { fuerza } \\
\text { el argu- } \\
\text { mento del } \\
\text { redactor }\end{array}$ & $\begin{array}{c}\text { e) Mención } \\
\text { meramente } \\
\text { ilustrativa } \\
\text { del desarrollo } \\
\text { del proceso }\end{array}$ \\
\hline Aborto tres causales & No & & & & & \\
\hline Semillas & No & & & & & \\
\hline Reforma laboral & No & & & & & Sí \\
\hline Píldora & No & & & & & \\
\hline Daño moral & Sí & & & & & \\
\hline $\begin{array}{l}\text { Libertades condicio- } \\
\text { nales }\end{array}$ & No & & & & & \\
\hline
\end{tabular}

Fuente: elaboración de los autores.

De lo anterior se concluye que argumentar haciendo referencia a las AP es más frecuente en votos minoritarios que en votos de mayoría. Esto denota que, cuando hay discrepancia, se busca apoyo en las argumentaciones que provienen desde la sociedad civil.

En cuanto al uso argumentativo que resulta más frecuente en las menciones de las audiencias, encontramos el uso (a) relativo a la incorporación de elementos técnicos y el uso (c) referente a la incorporación de interpretaciones jurídicas desde la sociedad civil. Esto refuerza que hay un equilibrio entre los dos objetivos institucionales de las AP previamente identificados.

\section{Atribuciones ejercidas y materias que se conocian en las sentencias que hacen referencias a las audiencias públicas}

Como se estableció previamente, para comprender la institución de las AP es relevante identificar la atribución que se ejerce por el tribunal cuando convoca a audiencias, y que da lugar a la sentencia constitucional en que se hace referencia a dicha audiencia. Así mismo, es esencial el tipo de materia sobre la cual trataba el caso en el que se convocó a esta. 
Tabla 6. Uso argumentativo de la mención de la audiencia pública en las sentencias

\begin{tabular}{|c|c|c|c|c|c|c|}
\hline Materia & Atribución & $\begin{array}{c}\text { a) In- } \\
\text { corpora } \\
\text { elementos } \\
\text { técnicos }\end{array}$ & $\begin{array}{l}\text { b) In- } \\
\text { corpora } \\
\text { elementos } \\
\text { fácticos }\end{array}$ & $\begin{array}{l}\text { c) Incorpora } \\
\text { argumentos } \\
\text { jurídicos } \\
\text { planteados por } \\
\text { participantes }\end{array}$ & $\begin{array}{l}\text { d) } R e- \\
\text { fuerza } \\
\text { el argu- } \\
\text { mento del } \\
\text { redactor }\end{array}$ & $\begin{array}{l}\text { e) Mención } \\
\text { meramente } \\
\text { ilustrativa } \\
\text { del desarrollo } \\
\text { del proceso }\end{array}$ \\
\hline $\begin{array}{l}\text { Aborto tres } \\
\text { causales }\end{array}$ & $\begin{array}{l}\text { CPF PDL } \\
93, \text { num. } 3\end{array}$ & Sí & Sí & Sí & Sí & Sí \\
\hline Semillas & $\begin{array}{l}\text { CPF TTII 93, } \\
\text { num. } 3\end{array}$ & & & Sí & & Sí \\
\hline $\begin{array}{l}\text { Reforma } \\
\text { laboral }\end{array}$ & $\begin{array}{l}\text { CPF PDL } \\
93, \text { num. } 3\end{array}$ & Sí & & & Sí & \\
\hline Píldora & $\begin{array}{l}\text { CC DS 93, } \\
\text { num. } 16\end{array}$ & Sí & & & & Sí \\
\hline Daño moral & $\begin{array}{l}\text { INC 93, } \\
\text { num. } 7\end{array}$ & & & & & Sí \\
\hline $\begin{array}{l}\text { Libertades } \\
\text { condicionales }\end{array}$ & $\begin{array}{l}\text { CPF PDL } \\
93, \text { num. } 3\end{array}$ & & & Sí & & \\
\hline
\end{tabular}

Fuente: elaboración de los autores.

En la tabla 6 se puede apreciar que la sentencia del caso 'aborto tres causales' es la que contiene más referencias a los argumentos vertidos en la AP convocada al efecto, aplicando todos los usos argumentativos que se han identificado. Esta causa tuvo amplia repercusión mediática por lo controversial del tema, con una mayor visibilidad pública, lo que implicó el interés de diversos sectores de la sociedad civil, trayendo como consecuencia, como ya se indicó, ser la única causa en que la sentencia presenta todos los usos argumentativos de las menciones a las AP.

En los casos 'aborto tres causales', 'reforma laboral' y 'píldora', la AP sirvió para incorporar elementos fácticos o técnicos a la argumentación de la sentencia.

En los casos 'aborto tres causales', 'semillas' y 'libertades condicionales', las AP sirvieron para incorporar argumentos jurídicos e interpretaciones constitucionales desde la sociedad civil hacia la argumentación de los jueces constitucionales. 
En los casos 'aborto tres causales' y 'reforma laboral', los argumentos jurídicos de las AP se usaron para reforzar el argumento del redactor de la sentencia o voto particular.

En la tabla 6 también se observa que, cuando se ejerce la atribución relativa al control preventivo facultativo de proyectos de ley, se hace más intensa la referencia a las AP, tanto en cantidad como en categorías de usos.

\section{Conclusiones}

Las AP convocadas por TCCh son una forma de participación de la sociedad civil que, pese a su importancia y a diferencia de otras experiencias en el continente, no cuentan con una regulación positiva que asegure que su convocatoria responderá a criterios definidos y previsibles. Tampoco su práctica permite identificar criterios sustantivos a la hora de determinar en qué materias proceden, o qué circunstancias hacen que resulte más probable que se convoque a estas audiencias.

Analizada una década de audiencias públicas, no ha sido posible determinar un patrón que permita identificar qué imagen pública o qué perfil desea cultivar el TCCh al momento de determinar la procedencia de las audiencias.

Sí pudimos concluir que la chance de que el TCCh convoque a AP aumenta significativamente cuando el tribunal se encuentra conociendo de un control preventivo facultativo de proyectos de ley. Esto puede vincularse con la búsqueda de mayores grados de legitimidad frente al ejercicio de una atribución cuestionada por su alta politicidad.

En relación con el impacto de las AP al momento de la adjudicación de los conflictos de constitucionalidad, se aprecia que en la gran mayoría de las causas en las que se convocó a audiencias estas no fueron siquiera mencionadas en la argumentación de la sentencia que resolvió el conflicto de constitucionalidad sometido a su conocimiento. Así, en la mayoría de las causas en que se convocó a AP, esto no impactó en la resolución del asunto.

En una minoría de los casos, las AP fueron mencionadas en la argumentación de las sentencias. En el estudio realizado identificamos que 
estas menciones cumplen los siguientes roles o usos argumentativos: incorporación de elementos técnicos, incorporación de elementos fácticos, incorporación de argumentos jurídicos planteados por participantes, reforzamiento del argumento jurídico del redactor y mención meramente ilustrativa del desarrollo del proceso. De estos, los más relevantes son el incorporar elementos técnicos y jurídicos aportados por los participantes de la AP. Esto es coincidente con los objetivos normativos que coexisten teóricamente en la institución de las AP: uno técnico o fáctico, que dice relación con que las AP amplían la participación para enriquecer la deliberación aportando antecedentes fácticos o técnicos que están fuera del ámbito de conocimiento de los jueces constitucionales. Y un segundo objetivo, normativo, que se vincula con el potencial democratizador y legitimador de las AP en el ejercicio de la jurisdicción constitucional al incorporar al proceso a otros intérpretes constitucionales. El estudio nos permitió confirmar la coexistencia de ambos objetivos institucionales en la realización de las AP, el técnico/ fáctico y el normativo, sin que pudiéramos concluir que uno es más relevante o frecuente que el otro.

De lo estudiado concluimos que las AP sí tienen potencial deliberativo, y pueden servir para abrir la interpretación constitucional, democratizar la justicia constitucional aumentando la deliberación y reforzar el conocimiento técnico del tribunal y de los aspectos de hecho involucrados en el caso, pero también concluimos que no ha sido esta la regla general.

Así, las conclusiones sobre el impacto de las AP en las decisiones del TCCh van en una línea similar a los hallazgos de las investigaciones del caso argentino y brasilero. Las AP no han tenido un impacto significativo en el enriquecimiento de la deliberación en el TCCh, ni para aportar elementos técnicos o fácticos, ni para aportar interpretaciones constitucionales desde la sociedad civil que se expresen en sus sentencias.

Retomando la inquietud inicial, el análisis de la argumentación de las sentencias que resuelven las causas en las que se ha convocado a AP por el TCCh demuestra que estas no han significado un enriquecimiento significativo de la deliberación. En todo caso, el optimismo teórico sobre el potencial deliberativo de las AP ha de ser moderado, pero no abandonado. Como dijimos, también este estudio vislumbra que es posible lograr dichos objetivos. Un mejoramiento del diseño de la institución, 
y su consolidación en la cultura de la justicia constitucional, podría mejorar su desempeño. Respondiendo a la pregunta que titula este trabajo, cuando se llama a hablar a la sociedad civil, el TCCh por regla general no escucha, pero ha demostrado que sí es capaz de escuchar.

Una configuración procesal adecuada podría hacer de las AP una herramienta valiosa para el enriquecimiento del debate dentro del proceso de control de constitucionalidad de la ley, sea para incorporar la visión de los sectores afectados por una decisión, sea para dar un espacio a los grupos vulnerables dentro del debate público, sea para incorporar elementos técnicos ajenos al conocimiento jurídico. Tratándose de una institución procesal que tiene a lo mucho una década de aparición en el continente, queda espacio para el optimismo.

\section{Referencias}

Abramovich, V. (2013). La apertura del debate constitucional. Nuevas vías de participación ante la Corte Suprema. Pensar en Derecho, (3), 17-23.

Ahumada, P. (2018). El Tribunal Constitucional en Chile: tres ensayos de justicia constitucional. En AA. VV., El sistema político de Chile (pp. 379-410). Santiago de Chile: LOM Ediciones.

Bassa, J. (2015). El Tribunal Constitucional en la Constitución chilena vigente. En J. Bassa, J. C. Ferrada, \& C. Viera, La Constitución chilena (pp. 253-284). Santiago de Chile: LOM Ediciones.

Benedetti, M., \& Sáenz, M. J. (2016). Las audiencias públicas de la Corte Suprema. Apertura y límites de la participación ciudadana en la justicia. Buenos Aires: Siglo XXI Editores.

Benedetti, M., \& Sáenz, M. J. (2018). Decisión judicial y participación ciudadana: los impactos de las audiencias públicas en las sentencias de la Corte Suprema argentina. Revista en Cultura de la Legalidad, (15), 102-122.

Correa, M., E Mendes, M. (2017). Democratizar a jurisdição constitucional? O caso das audiências públicas no Supremo Tribunal Federal. Revista de Sociología e Política, 25(62), 131-156.

Correia, J., Da Silva, I., \& Tenorio, F. (2018). As audiências públicas no STF: a adoção de um modelo cooperativo de controle de constitucionalidade das normas. Seqüência, (78), 175-198. 
Gargarella, R. (2013). El nuevo constitucionalismo dialógico, frente al sistema de los frenos y contrapesos. Revista Argentina de Teoría Jurídica, 14, 1-32.

Gargarella, R. (2019). La revisión judicial para las democracias latinoamericanas. En R. Niembro \& S. Verdugo (Coords.), La justicia constitucional en tiempos de cambio. México: Suprema Corte de Justicia de la Nación-ICON-S México.

Giuffré, C. (2016a). Audiencias públicas informativas en el poder judicial: una mirada a través de la obra de Jürgen Habermas. La Ley Online, AR/ DOC/1314/2016. Recuperado de https://www.academia.edu/21561380/ Audiencias_p\%C3\%BAblicas_informativas_en_el_Poder_Judicial_una_ mirada_a_trav\%C3\%A9s_de_la_obra_de_J\%C3\%BCrgen_Habermas

Giuffré, C. (2016b). Democracia deliberativa: institucionalización de instrumentos jurídico-dialógicos. Sistema Argentino de Información Judicial. Recuperado de https://www.academia.edu/25376685/Democracia_deliberativa_su_institucionalizaci\%C3\%B3n_a_trav\%C3\%A9s_de_instrumentos_jur\%C3\%ADdico-dial\%C3\%B3gicos

Grupo de Estudio de Reforma al Tribunal Constitucional. (2019). 25 propuestas para un Tribunal Constitucional del siglo XXI. Recuperado de https://www. cepchile.cl/documentos/Informe-Final-Grupo-Estudio-Reforma-al-TC.pdf

Häberle, P. (2008). La sociedad abierta de los intérpretes constitucionales: una contribución para la interpretación pluralista y 'procesal' de la Constitución. Revista sobre Enseñanza del Derecho, (6), 29-61.

Hennig, M. (2014). As audiências públicas no âmbito do Supremo Tribunal Federal brasileiro; uma nova forma de participação? Revista Novos Estudos Jurídicos, 19(2), 327-347.

Leal, F., Herdy, R., E Massadas, J. (2018). Uma década de audiencias públicas no Supremo Tribunal Federal (2007-2017). Revistas de Investigacoes Constitucionais, 5(1), 331-372.

Lorenzetti, R. (2013). Las audiencias públicas y la Corte Suprema. Revista Argentina de Teoría Jurídica, (14). Recuperado de http://www.utdt.edu/ ver_contenido.php?id_contenido $=9173 \mathcal{G i d}$ _item_menu $=5858$

Nosetto, L. (2018). Legitimidad democrática y judicialización de la política: el caso de la Argentina contemporánea. Ius Fugit: revista interdisciplinar de estudios histórico-jurídicos, (21), 145-166.

Pou, F. (2017). Supreme and Constitutional Courts: directions in constitutional justice. In R. Sieder E K. Ansolabehere (Coords.), Routledge handbook of law and society in Latin America (pp. 187-204). London: Routledge. 
Sacristán, E. (2009). Las audiencias públicas convocadas por la Corte Suprema argentina (¿más cerca o más lejos de las reglas de la Corte Suprema de los Estados Unidos). La Ley. Suplemento de derecho constitucional, 977-988. Sáenz, J., \& Barrera, L. (2020). Corte Suprema y participación ciudadana: reflexiones a partir de una audiencia pública de la Corte argentina. Estudios Socio-Jurídicos, 22(1), 263-291.

Sancari, S. (2015). El rol de la Corte Suprema de Justicia de la Argentina en el impulso de la participación política en la jurisdicción. Ecuador Debate, (96), 39-49.

Santos, T. (2017). Supremo Tribunal Federal representativo? O impacto das audiências públicas na deliberação. Revista Direito GV, 13(1), 236-273.

Sola, J. (2013). Audiencias públicas, amicus curiae y el caso Grupo Clarín. Pensar en Derecho, (3), 9-16.

Tushnet, M. (2015). New institutional mechanisms for making constitutional law. Harvard Public Law Working, (15-08). Recuperado de https://papers. ssrn.com/sol3/papers.cfm?abstract_id=2589178 